\title{
Perseverant, non-indicated treatment of obese patients for obstructive lung disease
}

\author{
Spyridon Fortis, Joseph Kittah, Manuel De Aguirre, Maria Plataki, Armand Wolff, Yaw Amoateng-Adjepong
} and Constantine A Manthous ${ }^{*}$

\begin{abstract}
Background: Bronchodilators are a mainstay of treatment for patients with airflow obstruction. We hypothesized that patients with obesity and no objective documentation of airflow obstruction are inappropriately treated with bronchodilators.

Methods: Spirometric results and medical records of all patients with body mass index $>30 \mathrm{~kg} / \mathrm{m}^{2}$ who were referred for testing between March 2010 and August 2011 were analyzed.

Results: 155 patients with mean age of $52.6 \pm(\mathrm{SE}) 1.1 \mathrm{y}$ and BMl of $38.7 \pm 0.7 \mathrm{~kg} / \mathrm{m}^{2}$ were studied. Spirometry showed normal respiratory mechanics in 62 (40\%), irreversible airflow obstruction in $36(23.2 \%)$, flows suggestive of restriction in 35 (22.6\%), reversible obstruction, suggestive of asthma in $11(7.1 \%)$, and mixed pattern (obstructive and restrictive) in 6 (3.9\%). Prior to testing, $45.2 \%$ (28 of 62) of patients with normal spirometry were being treated with medications for obstructive lung diseases and 33.9\% (21 of 62) continued them despite absence of airflow obstruction on spirometry. 60\% (21 of 35) of patients with a restrictive pattern in their spirometry received treatment for obstruction prior to spirometry and $51.4 \%$ (18 of 35) continued bronchodilator therapy after spirometric testing. There was no independent association of non-indicated treatment with spirometric results, age, BMI, co-morbidities or smoking history. All patients with airflow obstruction on testing who were receiving bronchodilators before spirometry continued to receive them after testing.

Conclusion: A substantial proportion of patients with obesity referred for pulmonary function testing did not have obstructive lung disease, but were treated nonetheless, before and after spirometry demonstrating absence of airway obstruction.
\end{abstract}

Keywords: Spirometry, Pulmonary function, Obesity, Asthma, Airflow obstruction, Restriction

\section{Background}

Previous studies have demonstrated over-diagnosis of asthma and chronic obstructive pulmonary disease (COPD) in adult populations [1-3]. There are also data to suggest that obese patients are more likely to report respiratory symptoms - especially dyspnea - more than non-obese patients [4]. Accordingly, we hypothesized that obese patients with respiratory complaints prompting pulmonary function tests would be at risk of mischaracterization and persistent, non-indicated treatment of obstructive lung disease.

\footnotetext{
* Correspondence: constantinemanthous@gmail.com

Department of Medicine, Bridgeport Hospital and Yale School of Medicine, New Britain, CT 06050, USA
}

\section{Methods}

The study protocol was exempted from review as set forth in the Code of Federal Regulations, 45 CFR 46.101(b) by the Bridgeport Hospital Institutional Review Board. Spirometric tests, conducted at Bridgeport Hospital between March 2010 and August 2011, were retrieved from the laboratory's electronic database. Spirometry was performed according American Thoracic and European Respiratory Society (ATS-ERS) guidelines [5-7] and patients were instructed not to take bronchodilators starting on the night prior to study. Metacholine broncho-provocation tests were performed when requested by the referring physician. Spirometric tests that were not considered acceptable by the reading pulmonologist were not enrolled. Interpretations of pulmonary function tests (PFTs)

\section{Biomed Central}


were performed by American Board of Internal Medicinecertified pulmonologists who applied ATS-ERS standards and guidelines [8]. Per these standards, obstruction is defined as reduced forced expired volume in 1 second: vital capacity (FEV1/VC) ratio below the 5th percentile of the predicted value. Asthma is defined as obstruction and increase in FEV1 and/or forced vital capacity (FVC) of $\geq 12 \%$ from baseline in response to bronchodilator, or a positive metacholine challenge test. A restrictive defect is defined as total lung capacity (TLC) below the 5th percentile of the predicted value. In the absence of measured lung volumes, a restrictive ventilatory defect is suggested by a reduced VC when FEV1/VC is increased (85-90\%) and the flow-volume curve demonstrates a convex pattern. A "mixed pattern" is defined as both FEV1/VC ratio and TLC below the 5th percentiles of their predicted values [8]. In our study, abnormal PFTs that could not be classified in any of the above categories using ATS-ERS standards and guidelines were categorized as inconclusive. Our lab does not measure VC routinely and the FVC was used for interpretation of function tests.

The following data were extracted from electronic medical records for all patients with body mass index $(\mathrm{BMI})>30 \mathrm{~kg} / \mathrm{m}^{2}$ : demographics, co-morbidities, smoking history, pre-testing pulmonary diagnosis, interpretation of spirometry, medications prior to testing, and medications following testing ( $\geq 6$ months later). Patients were excluded if they had no hospital medical records before and after the spirometry. We followed all the patients for a minimum of 6 months after spirometry. Logistic regression analysis was performed using Epi Info $^{\text {tx }}$ to identify variables associated with perseverant treatment of patients with bronchodilators in the absence of airflow obstruction on spirometry. Age, BMI, congestive heart failure (CHF), diabetes mellitus (DM), hypertension (HTN), sex and smoking were chosen as independent variables for modeling based on biological plausibility and/or if they demonstrated an association with inappropriate bronchodilator treatment in univariate analyses.

A $\mathrm{P}<0.05$ signified statistical significance.

\section{Results}

36 of 244 spirometries were considered technically unacceptable by the reading pulmonologist and were excluded from analysis. 208 patients with BMI $>30 \mathrm{~kg} / \mathrm{m}^{2}$ had acceptable spirometry during the study period, of whom 53 patients had no electronic records $\geq 6$ months after testing (Figure 1). Of the remaining 155 patients, $84 .(55 \%)$ were female, mean age was $52.6 \pm(\mathrm{SE}) 1.1 \mathrm{y}$ and BMI was $38.7 \pm 0.7 \mathrm{~kg} / \mathrm{m}^{2} .97(62.8 \%)$ had hypertension, $56(36.1 \%)$ diabetes mellitus and $13(8.4 \%)$ congestive heart failure (Table 1). The most common reasons for spirometry were dyspnea $(\mathrm{n}=43 ; 27.7 \%)$ and "COPD" (43; $27.7 \%)$, followed by "asthma" in (19; $12.3 \%)$, cough (13; 8.4\%), pre-operative evaluation $(12 ; 7.7 \%)$, not specified $(10 ; 6.5 \%)$, restrictive lung disease $(8 ; 5.2 \%)$ and obstructive sleep apnea $(7 ; 4.5 \%)$ (Figure 2). Fifty-seven patients also had measurements of lung volumes (which were interpreted in conjunction with spirometry).

Patients demonstrated a mean FEV1 of $66.6 \pm 1.4 \%$, mean FVC of $65.9 \pm 1.3 \%$ with an average FEV1/FVC ratio of $77.8 \%$ and a TLC of $82.7 \pm 3.7 \%$ of the predicted values (Table 2). Please refer to Table 2 for lung function descriptive statistics for each group.

Pulmonary testing was normal in $62(40 \%)$, showed irreversible airflow obstruction in 36 (23.2\%), restriction in 35 (22.6\%), reversible obstruction suggestive of asthma in 11

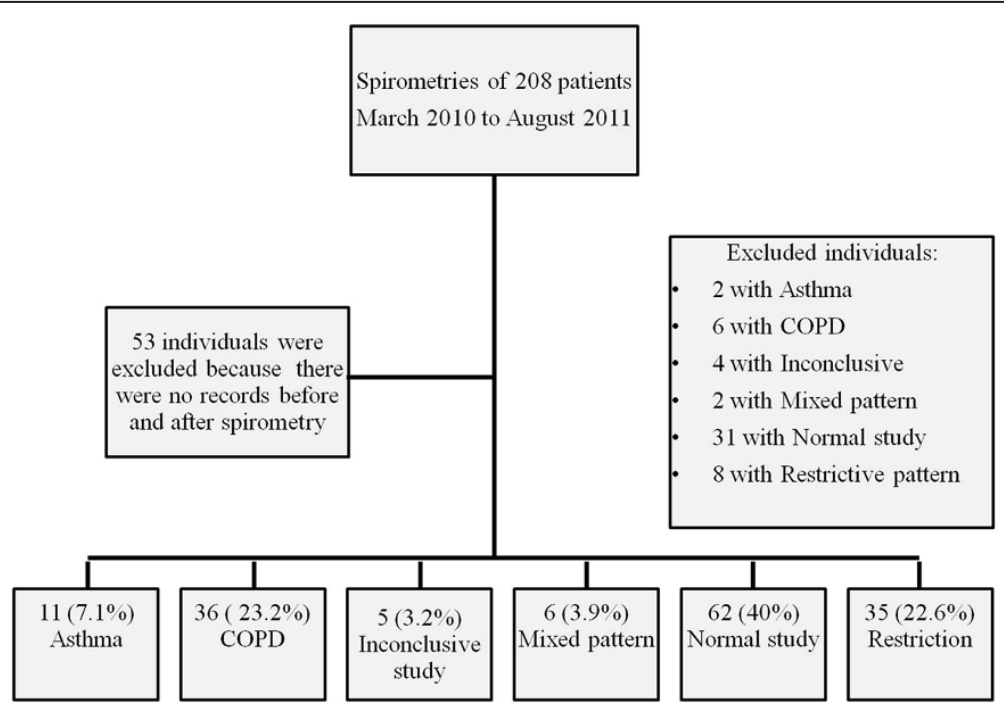

Figure 1 Selection of participants and diagnoses according to pulmonary function tests. 
Table 1 Characteristics of patients

\begin{tabular}{lc}
\hline \multicolumn{2}{c}{ Characteristics } \\
\hline Age (years) & $52.6 \pm 1.1$ \\
Body mass index $\left(\mathbf{k g} / \mathbf{m}^{2}\right)$ & $38.7 \pm 0.7$ \\
Female & $84(54.8 \%)$ \\
Hypertension & $97(62.8 \%)$ \\
Diabetes mellitus & $56(36.1 \%)$ \\
Congestive heart failure & $13(8.4 \%)$ \\
Active smokers & $48(23.1 \%)$ \\
\hline
\end{tabular}

Age and body mass index are presented as means and standard error. Gender, co-morbidities and smoking habit are presented in numbers and percentages of the study population.

(7.1\%), mixed pattern (obstructive and restrictive) in $6(3.9 \%)$ and inconclusive studies in $5(3.2 \%)$ patients (Figure 1). Prior to testing, 45.5\% (28 of 62) of patients with normal spirometry were being treated with medications for obstructive lung diseases; 15 (53.6\%) and 13 (46.4\%) of these 28 individuals were misdiagnosed with asthma and COPD, respectively. 33.9\% (21 of 62) of these patients continued treatments with medications for obstructive lung diseases despite absence of airflow obstruction on spirometry. 60\% (21 of 35) of patients with a restrictive pattern in their spirometry received treatment for obstruction prior to spirometry; 10 (47.6\%) and 6 (25.6\%) of these patients were misdiagnosed as asthma and COPD, respectively. And 86\% continued bronchodilator therapy despite spirometry results that did not demonstrate airway obstruction (Figure 3).

There was no independent association of non-indicated treatment with spirometric results, age, BMI, comorbidities or smoking (Table 3). All patients with airflow obstruction on testing who were receiving bronchodilators before spirometry ( 28 of 36 with irreversible

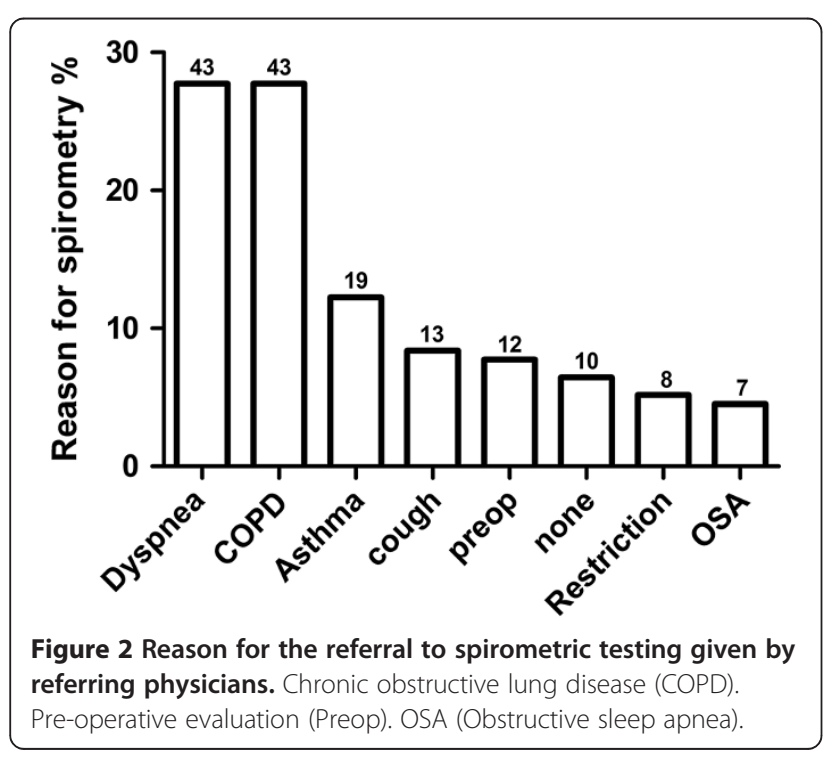

and 9 of 11 with reversible obstruction) continued to receive them after testing (Figure 3). Medications used to treat patients with normal tests included beta2-agonists in $40.3 \%$ (25 of 62), inhaled corticosteroids in $16.1 \%$ (10), anticholinergics in $14.5 \%$ (9), systemic corticosteroids in $8.1 \%$ (5) and leukotriene modifier in $1.6 \%$ (1). Individuals with restrictive pattern were prescribed beta2 agonists in 54.3\% (19 of 35), inhaled steroids in 28.6\% (10), anticholinergics in $14.3 \%$ (5), and (short-course) systemic corticosteroids $14.3 \%$ (5) (Table 4).

\section{Discussion}

This observational cohort study demonstrates that half of all obese patients referred for spirometry were treated empirically with bronchodilators before testing, and that even after spirometry demonstrated the absence of airflow obstruction $40 \%$ (39 of 97) continued to be prescribed therapies directed at obstructive lung disease 6 or more months after testing. Misdiagnosis of obstructive lung disease is not uncommon. Lindesmith and colleagues reported that many Canadian community clinicians diagnosed obstructive lung disease on clinical grounds; $41 \%$ of (37 of 90) patients were labeled as asthmatic but failed to meet diagnostic criteria [2]. As in our study, $62 \%$ of these misdiagnosed patients continued to receive inhaled beta-agonists, while $43 \%$ received inhaled glucocorticoids. In two separate studies, $30 \%$ of patients diagnosed with asthma on clinical grounds did not satisfy pulmonary function test criteria for obstruction $[3,9]$. In another study, $10-41 \%$ of patients in primary care offices used inhaled steroids for a clinical diagnosis of asthma or COPD without spirometric evidence to support the diagnoses [1].

We are unaware of a previous study that has focused on obese patients receiving spirometric testing. We focused on this population because they comprise a large demographic who commonly present with respiratory complaints [4], most often related to restrictive respiratory mechanics [10] and increased oxygen cost of breathing [4], and who might be - at least in theory more vulnerable to complications of unnecessary polypharmacy. While some studies have suggested an inverse relationship of BMI and FEV1 [11,12] and an association of obesity and obstructive lung diseases $[13,14]$, the frequency with which dyspnea is caused by obstructive vs. restrictive physiology in obese patients has not been well-studied. Obese patients are more likely to report respiratory symptoms - especially dyspnea -more than non-obese patients [4]. Truncal obesity can reduce chest wall compliance, and respiratory muscle strength and function [15]. Accordingly, we hypothesized that obese patients with respiratory complaints prompting pulmonary function tests would be at risk of mischaracterization and persistent, non-indicated treatment of 
Table 2 Lung function descriptive statistics

\begin{tabular}{lllllll}
\hline & Total & Asthma & COPD & Mixed & Normal & Restriction \\
\hline FEV1\% & $66.6 \pm 1.4$ & $59.9 \pm 6.4$ & $55.2 \pm 2.5$ & $50.1 \pm 5.7$ & $92.8 \pm 1.6$ & $66.6 \pm 2.8$ \\
FVC\% & $65.9 \pm 1.3$ & $74.3 \pm 5.3$ & $72.8 \pm 2.6$ & $61.5 \pm 7.6$ & $92.5 \pm 1.6$ & $65.9 \pm 2.7$ \\
FEV1/FVC\% & $77.8 \pm 1.1$ & $64 \pm 5.5$ & $58.9 \pm 1.9$ & $64.8 \pm 3.5$ & $81.5 \pm 0.9$ & $77.8 \pm 2.4$ \\
TLC\%* & $82.7 \pm 3.7$ & $97.2 \pm 6.4$ & $101.5 \pm 7.6$ & $66.6 \pm 4.6$ & $100.2 \pm 13.4$ & $69.1 \pm 1.4$ \\
\hline
\end{tabular}

Values are presented as means and standard error. FEV1, FVC and TLC are expressed as percentages of the predicted values. FEV1, forced expired volume in 1 second; FVC, forced vital capacity, TLC, total lung capacity. ${ }^{*} T L C$ was available for only 57 patients.

obstructive lung disease. Our results supported the hypothesis, but most surprising, treatments with medications for obstruction were continued without clinical or spirometric indications. Clearly such patients are exposed to complications and costs of these therapies without proven or plausible clinical benefits. Interestingly, the rate of bronchodilator use before and after PFTs remained the same in patients with COPD but decreased in those with asthma. We suspect this is a statistical artifact related to small sample size, nonetheless, it is a perseverant treatment. However, it could suggest bronchodilator prescription driven inappropriately by symptoms (i.e. dyspnea) rather than objective physiologic abnormalities.

We did not examine why clinicians continue to prescribe bronchodilators to patients whose function tests did not show obstruction. However, this phenomenon has been noted with other medications, most notably acid-suppressors. For example, Slain and colleagues demonstrated that 32 of 121 adult patients admitted to hospital reported taking either proton pump inhibitors or histamine-blocking agents [16]. Similarly, 62 of 213 patients admitted to the University of Michigan Hospital wards were receiving acid suppressors prior to admission, which increased to 152 of 213 during admission

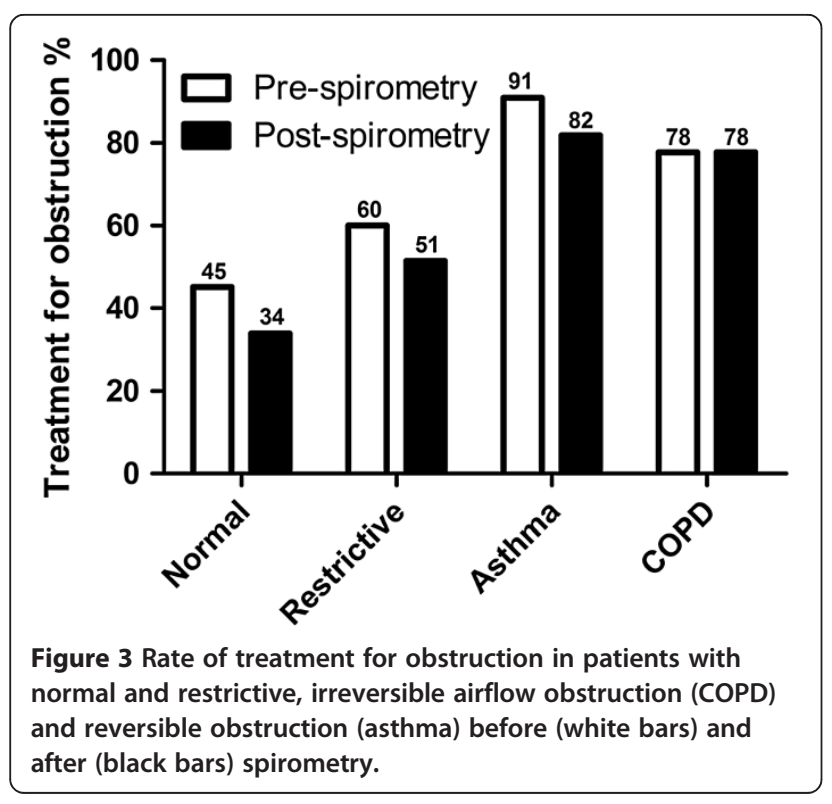

(only 15 "indicated"), and 115 of 213 were discharged on these medications [17]. The concept of "therapeutic inertia" has been introduced to describe situations in which clinicians fail to treat despite evidence of disease [18]. It is possible that perseveration of non-indicated acid suppression following hospitalization and bronchodilators without spirometric evidence of obstruction represent therapeutic inertia. Alternatively, perhaps this is a result of treatment bias; for example, if patients experience a placebo effect, there may be an inclination to continue a medication even without objective evidence of improvement.

Medication errors are a common cause of harm in hospitalized patients [19], and so appropriately the focus of regulatory scrutiny [20]. While perseverant treatment of our non-obstructed obese patients might be regarded as a "medication error," the genesis is probably more a malady of "systems-based practice." Too often disease entities are entered in the medical record without meeting firm diagnostic criteria; sometimes on the basis of medications administered presumptively [1-3]. Tests may be ordered but not checked or carefully considered to ensure that treatment regimens are appropriate [21]. Researchers are beginning to develop taxonomies for these diagnostic and therapeutic errors [21]. Arguably, the most important message is that diagnoses should not be taken "at face value"

Table 3 Adjusted odds ratios (ORs) and $95 \%$ confidence intervals (Cls) for determinants of treatment for obstructive airway disease among individuals with normal and restrictive pattern in their PFTs

\begin{tabular}{lccccccc}
\hline Spirometry & \multicolumn{3}{c}{ Normal } & & \multicolumn{3}{c}{ Restriction } \\
\cline { 2 - 4 } \cline { 7 - 8 } Term & OR & $\mathbf{9 5 \%}$ C.I. & P-Value & & OR & $\mathbf{9 5 \%}$ C.I. & P-Value \\
\hline Age & 1.00 & $0.95-1.04$ & 0.87 & & 1.10 & $1.00-1.21$ & 0.05 \\
BMI & 0.97 & $0.90-1.05$ & 0.51 & & 1.10 & $0.98-1.22$ & 0.10 \\
CHF & 2.24 & $0.16-30.66$ & 0.54 & & 0.18 & $0.02-1.87$ & 0.15 \\
DM & 2.05 & $0.59-7.15$ & 0.26 & & 0.07 & $0.00-1.77$ & 0.11 \\
HTN & 0.54 & $0.16-1.89$ & 0.34 & & $1.6 \times 10^{6}$ & $0.00-1 \times 10^{12}$ & 0.96 \\
Sex & 1.43 & $0.42-4.89$ & 0.57 & & 2.36 & $0.24-23.72$ & 0.46 \\
Smoking & 1.63 & $0.44-6.00$ & 0.47 & & 1.89 & $0.24-15.10$ & 0.55 \\
\hline
\end{tabular}

Adjustments were made for clinically relevant discriminators such as age, body mass index (BMI), congestive heart failure (CHF), diabetes mellitus (DM), hypertension (HTN), sex and smoking. 
Table 4 Treatment individuals received before spirometry

\begin{tabular}{lcccc}
\hline & Normal (62) & Restriction (35) & COPD (36) & Asthma (11) \\
\hline Inhaled Beta -agonists & $40.3 \%(25)$ & $54.3 \%(19)$ & $69.4 \%(25)$ & $72.7 \%(8)$ \\
Inhaled corticosteroids & $16.1 \%(10)$ & $28.6 \%(10)$ & $38.9 \%(14)$ & $63.6 \%(7)$ \\
Inhaled Anticholinergic & $14.5 \%(9)$ & $14.3 \%(5)$ & $33.3 \%(12)$ & $9.1 \%(1)$ \\
Oral corticosteroids & $8.1 \%(5)$ & $14.3 \%(5)$ & $13.9 \%(5)$ & $9.1 \%(1)$ \\
Leukotriene antagonists & $1.6 \%(1)$ & 0 & $5.6 \%(2)$ & $18.2 \%(2)$ \\
\hline
\end{tabular}

and perpetuated in medical records. Perhaps, reconciliation of medications and diagnoses will promote safer, patient-centered care. Specifically, our data combine with other studies $[9,22]$ to suggest that obesity is not - in itself - an obstructive, but rather is more commonly a restrictive lung disease. While obstructions may occur dynamically with sleep in these patients, and some obese patients may have true asthma or smoking-related obstructive disease, clinicians should exercise greater caution - via confirmatory spirometry - before assigning or perpetuating the label of obstructive lung disease to obese patients.

Mislabeling or misdiagnosis is not without risks and costs, especially when (these) patients receive medications that can cause complications but provide no proven benefit (since they did not have obstruction). In addition to tremor, tachycardia and hypokalemia, beta-agonists have been associated with increased mortality in asthmatic patients, especially African Americans [23]. Anticholinergic medications may also increase the risk of cardiovascular death [24]. Inhaled and systemic corticosteroids are associated with diabetes, hypertension, infection, pneumonia, glaucoma, adrenal insufficiency, thrush, dysphonia, myopathy, and cardiovascular events [25]. While we can find no suggestion that obese patients are more vulnerable to complications from these therapies, they could exacerbate some diseases (e.g. hypertension, diabetes) that are more common in the obese population.

Potential harm aside, our study has substantial financial implications. 33\% [26] of 246 million American adults [27] are overweight or obese. If half of the $2 \%$ of those with $\mathrm{BMI}>22.1 \mathrm{~kg} / \mathrm{m}^{2}$ who report asthma and take bronchodilators [22] really don't have reversible airflow obstruction, substantial unnecessary cost (and risks) accrues. At an average of $\$ 100 /$ year (for generic albuterol) [28], the total unnecessary cost - just for medication - is over $\$ 80$ million in the U.S. If more expensive medications are administered - tiotropium and salmeterol/fluticasone cost over \$1000/year [29]- unnecessary cost increases accordingly.

Our study has several limitations including its small sample size and sampling bias since our cohort represents only the subgroup of obese patients referred for pulmonary function testing. Since this study was conducted at only one hospital, these results should be generalized cautiously. But there is abundant evidence to suggest that incorrect diagnosis (and subsequent treatment) of obstructive lung disease occurs more globally [1-3,9]. Obese patients are not unique; but rather our results emphasize that pulmonary testing should be used to confirm or refute clinical impressions, and to guide appropriate management. In addition, lung volumes were not measured in $63 \%$ of patients. Vital capacity may differ from FVC in patients with substantial airway obstruction [30]. While airway obstruction was rare in our study population, this methodologic limitation, inherent in our retrospective study design, could reduce the precision of our conclusions. Another limitation of our study is that most (all but 2) individuals with normal spirometry did not have metacholine challenge to rule out bronchial hyper-responsiveness. In addition, although patients were instructed not to use bronchodilators for $>12$ hours, we did not ascertain the rate of compliance. However, that does not undermine the importance of our findings, since patients continued to receive bronchodilators even after function tests failed to demonstrate airflow obstruction. We cannot assert with certainty that bronchodilators were administered continuously/daily in all patients without indications in the follow-up period (i.e. in some the medications could have been stopped and later restarted for a bronchospastic episode that was not documented in our medical records). It is also possible that aerosols were administered to our patients for indications other than obstructive symptoms e.g. to improve mucociliary clearance [31]. However, since aerosols are seldom used solely for this indication in clinical practice, it is not unreasonable to assume that clinicians continued aerosols for (misdiagnosed) obstructive lung disease.

\section{Conclusion}

In conclusion, $45.2 \%$ (28 of 62 ) of obese individuals with normal PFTs and 60\% (21 of 35) with restrictive pattern received inappropriate treatment for obstructive lung disease prior to PFTs. Fully a third $(33.9 \%$; 21 of 62$)$ of these obese patients with normal lung mechanics, and half (51.4\%; 18 of 35$)$ with purely restrictive defects, continued to receive inappropriate treatment after function testing. A substantial number of individuals also received anticholinergics and inhaled and systemic steroids. Inappropriate use of these medications exposes patients to risks of complications and increases the cost of care with no proven or theoretical benefit. 


\section{Competing interests}

The authors declare that they have no competing interests.

\section{Authors' contributions}

SF participated in study design, data acquisition, data analysis, and manuscript preparation; CM and AW in study design and preparation of the manuscript; DA, JK and PM in data acquisition; AA in study design and data analysis. All authors approved the final content of the article.

Received: 24 May 2012 Accepted: 5 November 2013 Published: 22 November 2013

\section{References}

1. Lucas AE, Smeenk FW, Smeele IJ, van Schayck CP: Overtreatment with inhaled corticosteroids and diagnostic problems in primary care patients, an exploratory study. Fam Pract 2008, 25(2):86-91.

2. LindenSmith J, Morrison D, Deveau C, Hernandez P: Overdiagnosis of asthma in the community. Can Respir J 2004, 11(2):111-116.

3. Luks VP, Vandemheen KL, Aaron SD: Confirmation of asthma in an era of overdiagnosis. Eur Respir J 2010, 36(2):255-260.

4. Babb TG, Ranasinghe KG, Comeau LA, Semon TL, Schwartz B: Dyspnea on exertion in obese women: association with an increased oxygen cost of breathing. Am J Respir Crit Care Med 2008, 178(2):116-123.

5. Miller MR, Crapo R, Hankinson J, Brusasco V, Burgos F, Casaburi R, Coates A, Enright $P$, van der Grinten CP, Gustafsson P, et al: General considerations for lung function testing. Eur Respir J 2005, 26(1):153-161.

6. Miller MR, Hankinson J, Brusasco V, Burgos F, Casaburi R, Coates A, Crapo R, Enright P, van der Grinten CP, Gustafsson P, et al: Standardisation of spirometry. Eur Respir J 2005, 26(2):319-338.

7. Wanger J, Clausen JL, Coates A, Pedersen OF, Brusasco V, Burgos F, Casaburi R, Crapo R, Enright P, van der Grinten CP, et al: Standardisation of the measurement of lung volumes. Eur Respir J 2005, 26(3):511-522.

8. Pellegrino R, Viegi G, Brusasco V, Crapo RO, Burgos F, Casaburi R, Coates A, van der Grinten CP, Gustafsson P, Hankinson J, et al: Interpretative strategies for lung function tests. Eur Respir J 2005, 26(5):948-968.

9. Aaron SD, Vandemheen $\mathrm{KL}$, Boulet LP, Mclvor RA, Fitzgerald JM, Hernandez P, Lemiere C, Sharma S, Field SK, Alvarez GG, et al: Overdiagnosis of asthma in obese and nonobese adults. CMAJ 2008, 179(11):1121-1131.

10. Sharp JT, Henry JP, Sweany SK, Meadows WR, Pietras RJ: The Total Work of Breathing in Normal and Obese Men. J Clin Invest 1964, 43:728-739.

11. Wang ML, McCabe L, Petsonk EL, Hankinson JL, Banks DE: Weight gain and longitudinal changes in lung function in steel workers. Chest 1997, 111(6):1526-1532.

12. Bottai M, Pistelli F, Di Pede F, Carrozzi L, Baldacci S, Matteelli G, Scognamiglio A, Viegi G: Longitudinal changes of body mass index, spirometry and diffusion in a general population. Eur Respir J 2002, 20(3):665-673.

13. Beuther DA, Sutherland ER: Overweight, obesity, and incident asthma: a meta-analysis of prospective epidemiologic studies. Am J Respir Crit Care Med 2007, 175(7):661-666.

14. Vozoris NT, Stanbrook MB: Smoking prevalence, behaviours, and cessation among individuals with COPD or asthma. Respir Med 2011, 105(3):477-484.

15. McClean KM, Kee F, Young IS, Elborn JS: Obesity and the lung: 1. Epidemiology. Thorax 2008, 63(7):649-654.

16. Slain D, Kincaid SE, Dunsworth TS: Discrepancies between home medications listed at hospital admission and reported medical conditions. Am J Geriatr Pharmacother 2008, 6(3):161-166.

17. Pham CQ, Regal RE, Bostwick TR, Knauf KS: Acid suppressive therapy use on an inpatient internal medicine service. Ann Pharmacother 2006, 40(7-8):1261-1266.

18. Byrnes PD: Why haven't I changed that? Therapeutic inertia in general practice. Aust Fam Physician 2011, 40(1-2):24-28.

19. Leape LL, Brennan TA, Laird N, Lawthers AG, Localio AR, Barnes BA, Hebert L, Newhouse JP, Weiler PC, Hiatt H: The nature of adverse events in hospitalized patients. Results of the Harvard Medical Practice Study II. N Engl J Med 1991, 324(6):377-384.

20. Joint Commision: Using medication reconsiliation to prevent errors. http://www.jointcommission.org/assets/1/18/SEA_35.pdf.
21. Schiff GD, Kim S, Abrams R, et al: Diagnosing diagnosis errors: Lessons from a multi-institutional collaborative project. In Advances in Patient Safety: From Research to Implementation. http://www.ahrq.gov/qual/ advances/ Accessed April 23, 2012.

22. Sin DD, Jones RL, Man SF: Obesity is a risk factor for dyspnea but not for airflow obstruction. Arch Intern Med 2002, 162(13):1477-1481.

23. Nelson HS, Weiss ST, Bleecker ER, Yancey SW, Dorinsky PM: The Salmeterol Multicenter Asthma Research Trial: a comparison of usual pharmacotherapy for asthma or usual pharmacotherapy plus salmeterol. Chest 2006, 129(1):15-26.

24. Singh S, Loke YK, Furberg CD: Inhaled anticholinergics and risk of major adverse cardiovascular events in patients with chronic obstructive pulmonary disease: a systematic review and meta-analysis. JAMA 2008, 300(12):1439-1450.

25. UpToDate. http://www.uptodate.com/contents/major-side-effects-of-inhaledglucocorticoids.

26. Flegal KM, Carroll MD, Ogden CL, Curtin LR: Prevalence and trends in obesity among US adults, 1999-2008. JAMA 2010, 303(3):235-241.

27. United States Census Bureau: http://www.census.gov/compendia/statab/ cats/population.html. Accessed April 20, 2012.

28. Puig A, McElligott $S$, Bergquist $H$, Doshi JA: Albuterol and levalbuterol use and spending in Medicare beneficiaries with chronic obstructive pulmonary disease. Am J Geriatr Pharmacother 2010, 8(6):571-582.

29. Halpern R, Baker CL, Su J, Woodruff KB, Paulose-Ram R, Porter V, Shah H: Outcomes associated with initiation of tiotropium or fluticasone/ salmeterol in patients with chronic obstructive pulmonary disease. Patient Preference Adherence 2011, 5:375-388.

30. Chhabra SK: Forced vital capacity, slow vital capacity, or inspiratory vital capacity: which is the best measure of vital capacity? J Asthma 1998, 35(4):361-365

31. Sabater JR, Lee TA, Abraham WM: Comparative effects of salmeterol, albuterol, and ipratropium on normal and impaired mucociliary function in sheep. Chest 2005, 128(5):3743-3749.

doi:10.1186/1471-2466-13-68

Cite this article as: Fortis et al:: Perseverant, non-indicated treatment of obese patients for obstructive lung disease. BMC Pulmonary Medicine 2013 13:68

\section{Submit your next manuscript to BioMed Central and take full advantage of:}

- Convenient online submission

- Thorough peer review

- No space constraints or color figure charges

- Immediate publication on acceptance

- Inclusion in PubMed, CAS, Scopus and Google Scholar

- Research which is freely available for redistribution 